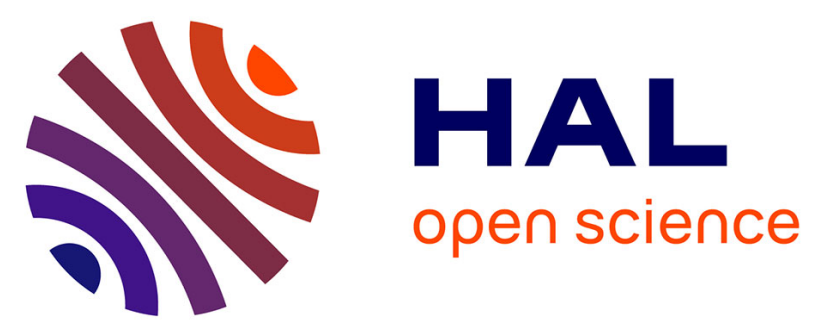

\title{
Bis[2-(methacryloyloxy)ethyl] phosphate radiografted into track-etched PVDF for uranium (VI) determination by means of cathodic stripping voltammetry
}

U. Pinaeva, T.C. Dietz, M. Al Sheikhly, E. Balanzat, M. Castellino, T.L. Wade, M.C. Clochard

\section{To cite this version:}

U. Pinaeva, T.C. Dietz, M. Al Sheikhly, E. Balanzat, M. Castellino, et al.. Bis[2(methacryloyloxy)ethyl] phosphate radiografted into track-etched PVDF for uranium (VI) determination by means of cathodic stripping voltammetry. Reactive and Functional Polymers, 2019, 142, pp.77-86. 10.1016/j.reactfunctpolym.2019.06.006 . hal-02273550

\author{
HAL Id: hal-02273550 \\ https://hal.science/hal-02273550
}

Submitted on 25 Oct 2021

HAL is a multi-disciplinary open access archive for the deposit and dissemination of scientific research documents, whether they are published or not. The documents may come from teaching and research institutions in France or abroad, or from public or private research centers.
L'archive ouverte pluridisciplinaire HAL, est destinée au dépôt et à la diffusion de documents scientifiques de niveau recherche, publiés ou non, émanant des établissements d'enseignement et de recherche français ou étrangers, des laboratoires publics ou privés.

\section{(c) (1) $\$$}

Distributed under a Creative Commons Attribution - NonCommerciall 4.0 International 


\title{
Bis[2-(methacryloyloxy)ethyl] phosphate radiografted into track-etched PVDF for uranium (VI) determination by means of cathodic stripping voltammetry
}

\author{
U. Pinaeva ${ }^{1}$, T. C. Dietz ${ }^{2}$, M. Al - Sheikhly ${ }^{2}$, E. Balanzat ${ }^{3}$, M. Castellino ${ }^{4,5}$, \\ T. L. Wade ${ }^{1}, \mathbf{M}$ - C. Clochard ${ }^{1 *}$ \\ ${ }^{1}$ Laboratoire des Solides Irradiés, CEA/DRF/IRAMIS, Ecole Polytechnique, CNRS \\ Institut Polytechnique de Paris, 91128 Palaiseau, France \\ ${ }^{2}$ Laboratory for Radiation and Polymer Science, Department of Materials \\ Science and Engineering A. J. Clark School of Engineering, \\ University of Maryland, College Park, MD, 20742 - 2115, USA \\ ${ }^{3}$ CIMAP, GANIL, 14000 Caen Cedex, France \\ ${ }^{4}$ Department of Applied Science and Technology, DISAT, Politecnico di Torino, \\ Corso Duca degli Abruzzi 24, 10129-Torino, Italy \\ ${ }^{5}$ Istituto Italiano di Tecnologia - IIT@ Polito, Via Livorno 60 - 10144 - Torino, Italy \\ *marie-claude.clochardepolytechnique.edu
}

\begin{abstract}
We report the radiation grafting of bis[2-(methacryloyloxy)ethyl] phosphate (B2MP) through electron-beam onto PVDF films and through swift heavy ions (SHI) irradiations into the pores of track-etched PVDF membranes. Radiolytically produced radicals were studied using EPR. To adapt the radiation grafting protocol inside the nanopores of track-etched membranes, the electron-beam irradiated films at varying monomer concentrations, doses and solvent mixtures were first studied. It was found that track-etched membranes, even after 1 hour of chemical treatment, do not require a post-etching irradiation to initiate free-radical polymerization of $\mathrm{B} 2 \mathrm{MP}$ from remaining radiationinduced radicals. The presence of functional groups inside the nanopores of the membrane were examined using FTIR and XPS. After exposure of B2MPg-PVDF membranes to a uranyl solution, XPS was also exploited to evidence of $\mathrm{O}_{2} \mathrm{UO}_{2}^{2+}$ trapping inside the membrane nanoporosity by tracking the presence of $\mathrm{U} 4 \mathrm{f}$ peak. The B2MP-g-PVDF membranes were converted into electrodes by depositing $35 \mathrm{~nm}$ of gold on each side through a mask. Detection of ppb concentrations (from 20 to $100 \mathrm{ppb}$ ) of uranyl by B2MP-g-PVDF membrane electrodes was demonstrated by means of square wave cathodic stripping voltammetry (SW-CSV). The limit of detection (LOD) was estimated to be 17 $\operatorname{ppb}\left(3 \sigma_{7}\right.$ slope $)$.
\end{abstract}

Key words: uranyl, track-etched membrane, radiation grafting, stripping voltammetry

\section{Introduction}

The International Guidelines for Drinking Water Quality of the World Health Organization (4th edition, 2011) has recommended a value for uranium of $30 \mathrm{ppb}$ (or $\mu \mathrm{gL}^{-1}$ ) 
for waters intended for human consumption [1]. However, this limit may not protect specifically sensitive populations, such as children and people with predispositions for hypertension or osteoporosis [2,3]. Common analytical techniques involve ICP-MS [4] and radio-metric analyses [5]. However, these methods are neither accessible nor suitable for daily field work and tests. Additionally, they are expensive and not portable. Thus, removal and accurate analysis of low uranium concentrations in drinking water are necessary.

Uranium is a natural element that exists in various oxidation states, namely $+2,+3$, $+4,+5$, and +6 . The most common and thermodynamically stable form of dissolved uranium is uranyl ion, ${ }^{V I} \mathrm{O}_{2} \mathrm{U}^{\mathrm{VI}} \mathrm{O}_{2}^{2+}$. The uranyl ion has a linear structure with two nonreactive double uranium-oxygen bonds, and it tends to create a complex with six ligands at the most, leaving the $\mathrm{U}=\mathrm{O}$ bonds unaltered [6]. Being a hard Lewis acid, uranyl has more affinity for hard bases. The compounds, containing oxygen or nitrogen atoms, as well as phosphate or carbonate anions, are good candidates for uranium trapping [7]. Recently developed oxalate-based adsorbents made by radiation grafting of diallyl oxalate onto polyamide 6 fabrics maintain high uranium capacity comparable with amidoximated resins [15]. Five years ago, a polymeric chelating resin was prepared by growing third generation poly(amido)amine (PAMAM) dendron on the surface of styrene divinylbenzene (SDB) [16]. The main advantage of a dendron structure is that it contains a significant quantity of nitrogen and oxygen atoms from the amino and amide groups, which produce a strong chelating effect. PAMAM modified poly(SDB) adsorbent, carrying phosphorus functional groups, has exhibited superior adsorption characteristics with high complexation rates, capacity and selectivity [17]. Indeed, the poly(ethylene glycol methacrylate phosphate) macroporous membranes made by means of radiation grafting onto poly(propylene) fibrous sheets have shown a high pre-concentration effect due to the presence of phosphate groups [18]. In nature, phosphates have been found complexed with uranium in ore deposits $[19,20]$. It is also well known that di-(2-ethylhexyl) phosphoric acid and trioctylphosphine oxide are used for uranium extraction from liquid acidic solutions [21]. Thus, phosphate containing materials have already proved their efficacy in extracting uranium from aqueous solutions.

Electrochemical analysis has a major advantage over aforementioned methods, as it allows speciation of uranium in solution by direct measurement. Also, voltammetry is an easy-to-use, sensitive, fast, portable and relatively cheap technique, enabling the performance of on-site analysis. There are not many reports about electrochemical detection of uranium. Peled et al. report the determination of uranyl using gold microelectrodes by anodic stripping voltammetry [22]. Another technique among the few is to use a gold electrode chemically modified by $\mathrm{POCl}_{3}$ capable quantifying $\mu \mathrm{M}$ uranyl concentrations [23]. Recently, nanostructured materials are becoming a trend in heavy metal extraction from water due to the improved trapping properties. Nevertheless, there is no method for uranyl determination by means of functionalized nanoporous membrane electrodes. Bis[2-(methacryloyloxy)ethyl] phosphate (B2MP), $\left[\mathrm{H}_{2} \mathrm{C}=\mathrm{C}\left(\mathrm{CH}_{3}\right) \mathrm{CO}_{2} \mathrm{CH}_{2} \mathrm{CH}_{2} \mathrm{O}\right]_{2} \mathrm{P}(\mathrm{O}) \mathrm{OH}$, is one among a few commercially available phosphate containing monomers which might be used for uranium extraction. Additionally, the availability of two vinyl groups allows B2MP to be grafted onto an irradiated polymer. 
The current study presents radiation grafting of B2MP onto electron-beam irradiated polyvinylidene fluoride (PVDF) films and inside the nanopores of track-etched PVDF membrane. The goal is to show the capability of such a nanostructured material to preconcentrate uranyl from aqueous solutions and its ability to be analized using voltammetry. Our study is one of the few reports relating to on-site uranyl sensing. The B2MP-g-PVDF membrane electrodes were fabricated according to the previous works of our team $[24,25]$. Electron paramagnetic resonance spectroscopy (EPR) was used to analyze radiolytically produced radicals. Field-emission scanning electron microscopy (FESEM) was used to examine morphology of the PVDF track-etched membrane surface. Fourier-transform infrared spectroscopy (FTIR) and X-ray photoelectron spectroscopy (XPS) were utilized to verify the presence of functional groups inside the nanopores of the membrane. Square-wave cathodic stripping voltammetry (SW-CSV) was used to plot a calibration curve and to demonstrate sensitivity toward trapped $\mathrm{O}_{2} \mathrm{UO}_{2}^{2+}$ in trace level (LOD is $17 \mathrm{ppb}$ ).

\section{EXPERIMENTAL SECTION}

2.1. Materials and instruments. Semi-crystalline $\beta$-polyvinylidene fluoride (PVDF) films of $9 \mu \mathrm{m}$ thickness (about $40 \%$ crystallinity) were provided by PiezoTech SA. Potassium hydroxide, potassium permanganate, Mohr's salt $\left(\left(\mathrm{NH}_{4}\right)_{2} \mathrm{Fe}\left(\mathrm{SO}_{4}\right)_{2} \cdot 6 \mathrm{H}_{2} \mathrm{O}\right)$, sodium metabisulphite $\left(\mathrm{Na}_{2} \mathrm{~S}_{2} \mathrm{O}_{5}\right)$, bis[2-(methacryloyloxy)ethyl] phosphate (B2MP), ethanol were purchased from Sigma-Aldrich. Uranyl acetate (Polysciences, Inc.) was used in the preparation $\mathrm{O}_{2} \mathrm{UO}_{2}^{2+}$-spiked water. Acetate buffer was prepared using acetic acid (glacial, 100\% unhydrous, Merck) and anhydrous sodium acetate (Alfa Aesar). Deionized water was used for preparing all the solutions. The orbital shaker (Heidolph) was used to perform the B2MP-g-PVDF membrane electrodes adsorption. A PalmSens potentiostat (The Netherlands) was used for all voltammetric tests.

2.2. Irradiation. Swift-heavy ion (SHI) irradiations were performed at GANIL, France. PVDF films were irradiated at room temperature with ${ }_{136} \mathrm{Xe}^{48+}\left(7.46 \mathrm{MeV} \cdot \mathrm{amu}{ }^{-1}\right)$ under He atmosphere. The films $(4 \mathrm{~cm} \times 30 \mathrm{~cm})$ were anchored on movable sample holders. Fluence was adjusted taking into account number of passages and the ion beam flux. For all the results the fluence was $10^{10} \mathrm{~cm}^{-2}$. Conversion of the fluence to adsorbed dose in the polymer was calculated by formula:

$$
\operatorname{Dose}(G y)=1.6 \cdot 10^{-7} \cdot f \cdot \frac{d E}{d x},
$$

where $f$ is ion fluence, $\mathrm{cm}^{-2}, \frac{d E}{d x}$ is the massic stopping power, $\mathrm{MeV} \cdot \mathrm{mg}^{-1} \cdot \mathrm{cm}^{2}$, $1 \cdot 67 \cdot 10^{-7}, \mathrm{~J} \cdot \mathrm{mg} \cdot \mathrm{MeV}^{-1} \cdot \mathrm{kg}^{-1}$, is a conversion constant. For instance, the ion fluence of $10^{9} \mathrm{~cm}^{-2}$ for SHI irradiated films corresponds to $7.6 \mathrm{kGy}$ dose.

Electron-beam irradiations were performed at the SIRIUS facility (Laboratoire des Solides Irradiés, Ecole Polytechnique, France). Films were irradiated at room temperature under $\mathrm{He}$ atmosphere with accelerating voltage of $2.5 \mathrm{MeV}$ and machine current of $1.4 \mu \mathrm{A}$. Doses were 5, 7.5, 10,50 and $100 \mathrm{kGy}$. All the irradiated samples were immediately stored at $-20^{\circ} \mathrm{C}$ under anaerobic conditions to prevent from oxidation. 
2.3. Chemical etching. $\beta$-PVDF SHI irradiated films were chemically etched using $10 \mathrm{M} \mathrm{KOH}$ and $0.25 \mathrm{M} \mathrm{KMnO}_{4}$ solutions at $65^{\circ} \mathrm{C}$ for $25 \mathrm{~min}$. The etched membranes were washed with aqueous solution of $\mathrm{Na}_{2} \mathrm{~S}_{2} \mathrm{O}_{5}(7.5 \mathrm{wt} \%)$ to reduce the remaining active $\mathrm{KMnO}_{4}$, followed by rigorous rinsing by deionized water. The diameter of obtained cylindrical nanopores depends on the etching duration. After 25 min etching of films exposed to a $10^{10} \mathrm{~cm}^{-2}$ fluence the resulting mean pore diameter was $60 \pm 5 \mathrm{~nm}$.

2.4. Radiation grafting of B2MP. The electron-beam irradiated films or tracketched PVDF membranes were placed in purgeable glass tubes containing B2MP monomer solutions. To avoid undesired homopolymerization reaction, we followed indirect grafting. However, Mohr's salt $(632 \mathrm{mg} / 100 \mathrm{~mL})$ was used in each radiation grafting procedure to suppress possible gel formation, and thereby to increase the grafting yields onto the surface of PVDF. The purgeable glass tubes were then connected to a Schlenk line for oxygen elimination. After $15 \mathrm{~min}$ of $\mathrm{N}_{2}$ purging at room temperature, they were then sealed and put into a thermostat water bath at $65^{\circ} \mathrm{C}$ for various times. The grafted films were washed with ethanol and dried at room temperature. Gravimetrical grafting yields (GY) were calculated by formula (2).

$$
G Y=\frac{m_{\text {final }}-m_{\text {initial }}}{m_{\text {initial }}} \times 100 \%,
$$

where $\mathrm{m}_{\text {initial }}$ and $\mathrm{m}_{\text {final }}$ are masses of film weighed before and after radiation grafting respectively.

\subsection{Characterization of B2MP-g-PVDF membranes.}

Electron paramagnetic resonance spectroscopy (EPR) was used to examine radiationinduced changes in PVDF films. The measurements were carried out at room temperature using a Bruker EMX spectrometer with $9.85 \mathrm{GHz}$ at $18.4 \mathrm{~mW}$ power and $100 \mathrm{kHz}$ field modulation frequency. The radical consumption was determined through the ratio of signal intensity and the receiver gain multiplied by the mass of the sample. Membranes topologies were checked after each fabrication step using Field-Emission Scanning Electron Microscopy (FESEM). FESEM micrographs were acquired with Hitachi S-4800 microscope at $1 \mathrm{kV}$ accelerating voltage and $7 \mu \mathrm{A}$ current. B2MP grafting was followed by Fourier-Transform InfraRed spectroscopy (FTIR) and X-ray Photoelectron Spectroscopy (XPS). FTIR spectra were obtained with the Nicolet iS50 FT-IR spectrometer (Thermo scientific). Spectra were recorded in absorption mode by cumulating of 64 scans with resolution of $2 \mathrm{~cm}^{-1}$. XPS spectra were conducted on a PHI 5000 VersaProbe (Physical Electronics) instrument. An Al K- $\alpha(1486.6 \mathrm{eV})$ monochromatic X-ray source was used. A $187.85 \mathrm{eV}$ pass energy value was used for survey spectra and $23.5 \mathrm{eV}$ for high resolution (HR) peaks. Charge compensation was accomplished with a combined electron and Ar neutralizer system. The binding energies were calibrated by fixing the $\mathrm{C}$ 1s binding peak to $284.5 \mathrm{eV}$. XPS spectra also allowed the detection of trapped U(VI) in B2MP-g-PVDF membranes. The P2p signal has been acquired during 10-15 min (around 50 scans) for undoped samples and during 30-40 min (roughly 150 scans) for U(VI) doped samples.

2.6. Voltammetry. Track-etched B2MP-g-PVDF membranes were converted into 
electrochemical nanoporous sensors by depositing $35 \mathrm{~nm}$ of gold on each side of the membrane through a mask. The gold on one side of the membrane serves as working electrode while the other one serves as counter electrode. Both gold surfaces $(0.8 \mathrm{~cm}$ of diameter $=0.502 \mathrm{~cm}^{2}$ ) were connected to a potentiostat. A chlorinated Ag wire acts as pseudo-reference electrode. A cyclic voltammogram (CV) was first performed on a B2MP-g-PVDF membrane electrode in a blank solution of acetate buffer $(50 \mathrm{mV})$ and $0.1 \mathrm{M}-\mathrm{KNO}_{3}(\mathrm{pH} 3)$ (figure 1). Despite the thin Au layer, a typical profile of amorphous $\mathrm{Au}$ electrode was registered. Integration of reduction peak at $0.62 \mathrm{~V}$ corresponding to one monolayer of $\mathrm{Au}$ oxide formed during the positive scan leads to a charge of around $300 \mu \mathrm{C}$. Taking in account the charge of gold monolayer of $482 \mu \mathrm{C} . \mathrm{cm}^{-2}$ [26], an electroactive surface area of $0.622 \mathrm{~cm}^{2}$ was found.

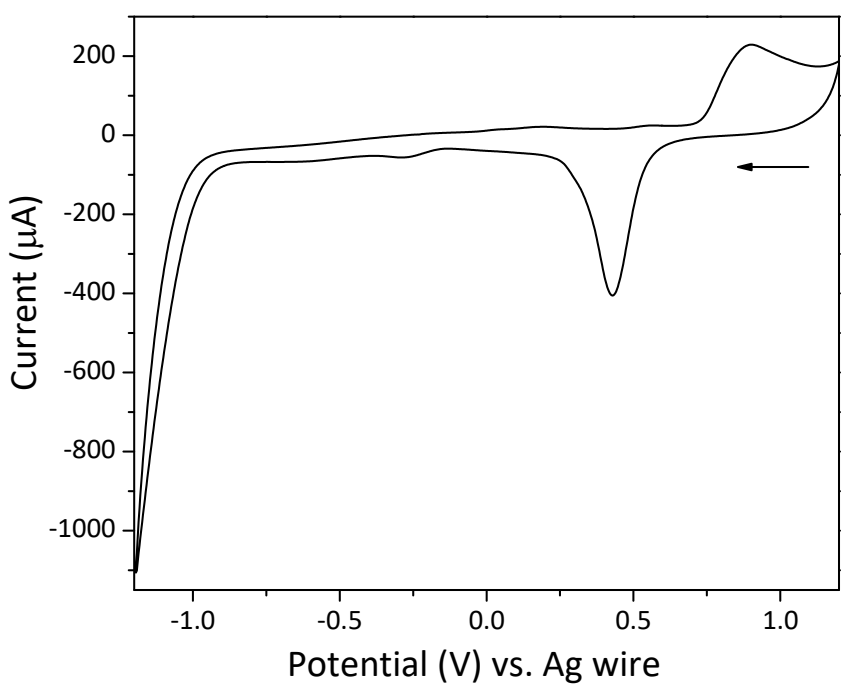

Figure 1. CV of B2MP-g-PVDF membrane-electrode of $0.8 \mathrm{~cm}$ of diameter recorded in $50 \mathrm{mM}$ acetate buffer and $100 \mathrm{mM} \mathrm{KNO}_{3}\left(\mathrm{pH}\right.$ 3) electrolyte at a scan rate of $100 \mathrm{mV} \cdot \mathrm{s}^{-1}$.

The sensors were then immersed in the aqueous solutions of uranyl acetate to adsorb uranyl. During stirring, the solvated $\mathrm{UO}_{2}^{2+}$ ions are complexed with phosphate groups of B2MP in the subporous region of the membrane, thus the trapped ions can be analyzed by means of voltammetry. Applying a potential of $+1.2 \mathrm{~V}$ during 300 sec permits oxidation of adsorbed species on the cathode. After this deposition time, quantitative analysis was performed by registering the charge of $\mathrm{UO}_{2}^{2+}$ reduction peak when applying square-wave cathodic stripping voltammetry (SW-CSV). The potential was negatively scanned from $+1.2 \mathrm{~V}$ to $-1.2 \mathrm{~V}$ with step potential of $3 \mathrm{mV}$, frequency of $20 \mathrm{~Hz}$ and amplitude of $30 \mathrm{mV}$. A mixture of $50 \mathrm{mM}$ acetate buffer and $0.1 \mathrm{M} \mathrm{KNO}_{3}$ (pH3) was used as electrolyte. Each current peak height of U(VI) reduction peak corresponds to an average value of 3 registered SW-CSV measurements referred to 3 distinct B2MP-g-PVDF membrane-electrodes from the same batch. 


\section{RESULTS AND DISCUSSION}

3.1 Radiation-induced radical polymerization in PVDF films. Whatever the irradiation process (electrons or ions), the irradiation of PVDF films, $-\left[\mathrm{CH}_{2}-\mathrm{CF}_{2}\right]_{n}-$, yields $\mathrm{H}_{2}$ and $\mathrm{HF}$ gas release [27], crosslinking, double bond formation (for example, $-\mathrm{CF}_{2^{-}}$, $\left.\mathrm{CH}=\mathrm{CF}_{2},-\mathrm{CH}=\mathrm{CF}-\right)$ [28], in addition to the formation of alkyl radicals [29, 30]. These free radicals are $-\mathrm{CF}_{2}-\mathrm{C}^{\cdot} \mathrm{H}_{2},-\mathrm{CH}_{2}-\mathrm{C}^{\cdot} \mathrm{F}_{2},-\mathrm{CF}_{2}-\mathrm{C} \cdot \mathrm{H}-\mathrm{CF}_{2},-\mathrm{CH}_{2}-\mathrm{C}^{\cdot} \mathrm{F}-\mathrm{CH}_{2}$ [31]. The radicals react with molecular oxygen to produce the corresponding peroxyl radicals (ROO ${ }^{\circ}$ ). There is thus the coexistence of two types of radicals, alkyl and peroxyl, present in the irradiated PVDF films.

Due to the semi-crystalline structure of PVDF of about $40 \%$, there is still a considerable amount of radicals trapped in the crystallites, and at the interfaces between the crystalline and amorphous regions [32]. The addition of the alkyl radicals to the double bonds of B2MP monomer initiates the polymerization reaction. Simultaneously, the peroxyl radicals also initiate, to some extent, the polymerization reaction.

Trapped radicals, formed by breaking lateral bonds of polymer, initiate polymerization reaction in presence of monomer (eq. 4). After the initiation, the propagation of monomer chains takes place (eq. 5). The process continues until the growing macro-radicals meet each other (recombination) and thus terminate the chain growth (eq. 6).

$$
\begin{gathered}
\mathrm{RH} \underset{\text { vacuum }}{\stackrel{\text { irradiation }}{\rightarrow}} \mathrm{R}^{\cdot}+\mathrm{H}^{\cdot} \\
\mathrm{R}^{\cdot}+\mathrm{M} \rightarrow \mathrm{RM}^{\cdot} \\
\mathrm{RM}^{\cdot}+\mathrm{nM} \rightarrow \mathrm{RM}_{\mathrm{n}+1}^{\cdot} \\
\mathrm{RM}_{\mathrm{n}}^{\cdot}+\mathrm{RM}_{\mathrm{m}}^{\cdot} \rightarrow \mathrm{RM}_{\mathrm{n}+\mathrm{m}}
\end{gathered}
$$

When the polymer substrate is irradiated under an oxygen (or air) atmosphere or was exposed to air after irradiation, peroxides or hydroperoxides due to oxidation of alkyl radicals are formed (eqs. 7-9). At elevated temperature, the peroxide bonds decompose on alkoxy and hydroxy radicals (eq. 10). The alkoxy radicals can then initiate the polymerization reaction when put in contact with monomer solution (eq. 11).

$$
\begin{gathered}
\mathrm{RH}^{\stackrel{\text { irradiation }}{\mathrm{O}_{2 /} \text { air }}} \mathrm{R}^{\cdot}+\mathrm{H}^{\cdot} \\
\mathrm{R}^{\cdot}+\mathrm{O}_{2} \rightarrow \mathrm{ROO}^{\cdot} \\
\mathrm{ROO}^{\bullet}+\mathrm{RH} \rightarrow \mathrm{ROOH}+\mathrm{R}^{\cdot} \\
\mathrm{ROOH}^{\rightarrow} \mathrm{RO}^{\cdot}+\mathrm{OH}^{\cdot} \\
\mathrm{RO}^{\cdot}+\mathrm{M}^{\cdot} \rightarrow \mathrm{ROM}^{\cdot} \\
\mathrm{ROM}_{\mathrm{n}}^{\cdot}+\mathrm{ROM}_{\mathrm{m}}^{\cdot} \rightarrow \mathrm{ROM}_{\mathrm{n}+\mathrm{m}}
\end{gathered}
$$

3.2. Electron-beam induced grafting of B2MP onto PVDF. In order to determine the optimal radiation grafting parameters, the electron-beam irradiated films at various 
doses were first grafted with B2MP. During electron beam irradiation, the energy is randomly deposited in polymer bulk and subsequent radio-grafted copolymer chains are also homogeneously distributed. Figure 2 shows the EPR spectra of radiation-induced species in the electron-beam irradiated PVDF films at 5, 7.5 and $10 \mathrm{kGy}$ doses $[25,32,33]$. It should be mentioned, precautions were made to ensure the absence of oxygen during irradiation. After irradiation, the samples were exposed to oxygen during transferring allowing the formation of the peroxyl radicals.

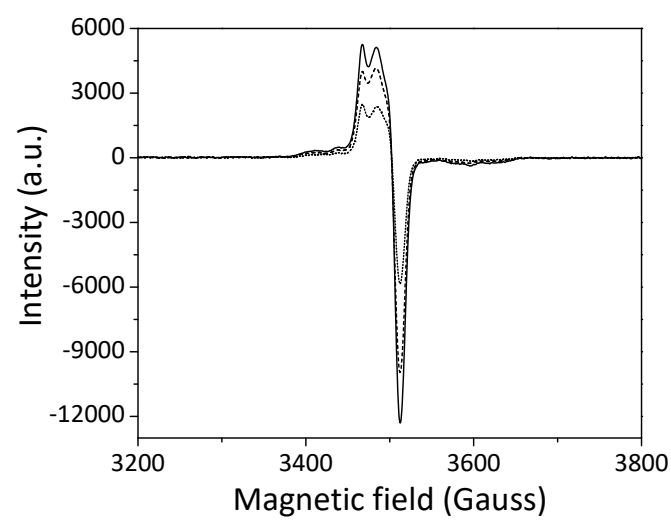

Figure 2. EPR spectra of electron-beam irradiated $9 \mu$ m thickness PVDF films at different doses: $5 \mathrm{kGy}$ (dotted line), $7.5 \mathrm{kGy}$ (dashed line), $10 \mathrm{kGy}$ (solid line). Calculated $g$-value equals to 2.008 for central field of 3502.7 Gauss.

As shown in figure 3a, the grafting yield (GY) increases up to $7 \mathrm{wt} . \%$ as a function of B2MP concentration. However, the GY starts decreasing for the higher B2MP concentrations. This can be interpreted by the fact that after exceeding of $100 \mathrm{mM}$ B2MP, the electron transfer reactions between the growing grafting chains and the monomer become predominant, leading to termination of the graft polymerization reaction. As mentioned earlier, the homopolymerization reaction is not expected to occur in our experimental conditions. The role of the solvent is to enhance the solid polymer swelling during radical polymerization through the growing grafted polymer chains. Consequently, a good solvent should be both a good solvent for the monomer and its polymer facilitating the monomer accessibility to radical sites. The use of good-swelling solvent results in bulk and homogeneous grafting. A mixture of 50 vol. $\%$ water and 50 vol. $\%$ ethanol was used as a solvent.

The grafted B2MP-g-PVDF films were washed with ethanol, weighed and analyzed by FTIR. A FTIR peak at $1725 \mathrm{~cm}^{-1}$ associated with a carbonyl group of B2MP was measured each time to confirm the presence of functional polymer onto PVDF surface. For a given dose, $100 \mathrm{kGy}, 100 \mathrm{mM}$ B2MP concentration and the solvent composition of $50 \mathrm{vol} . \%$ water and $50 \mathrm{vol} . \%$ ethanol were found to give the highest GY (figure $3 b$ ). The same procedure was carried out for the electron-beam irradiated PVDF films at different doses. GYs should vary proportionally with the dose as the radical content gradually increases as shown in figure 2. Gravimetrical yield was found linearly increasing with dose (figure 3c). 

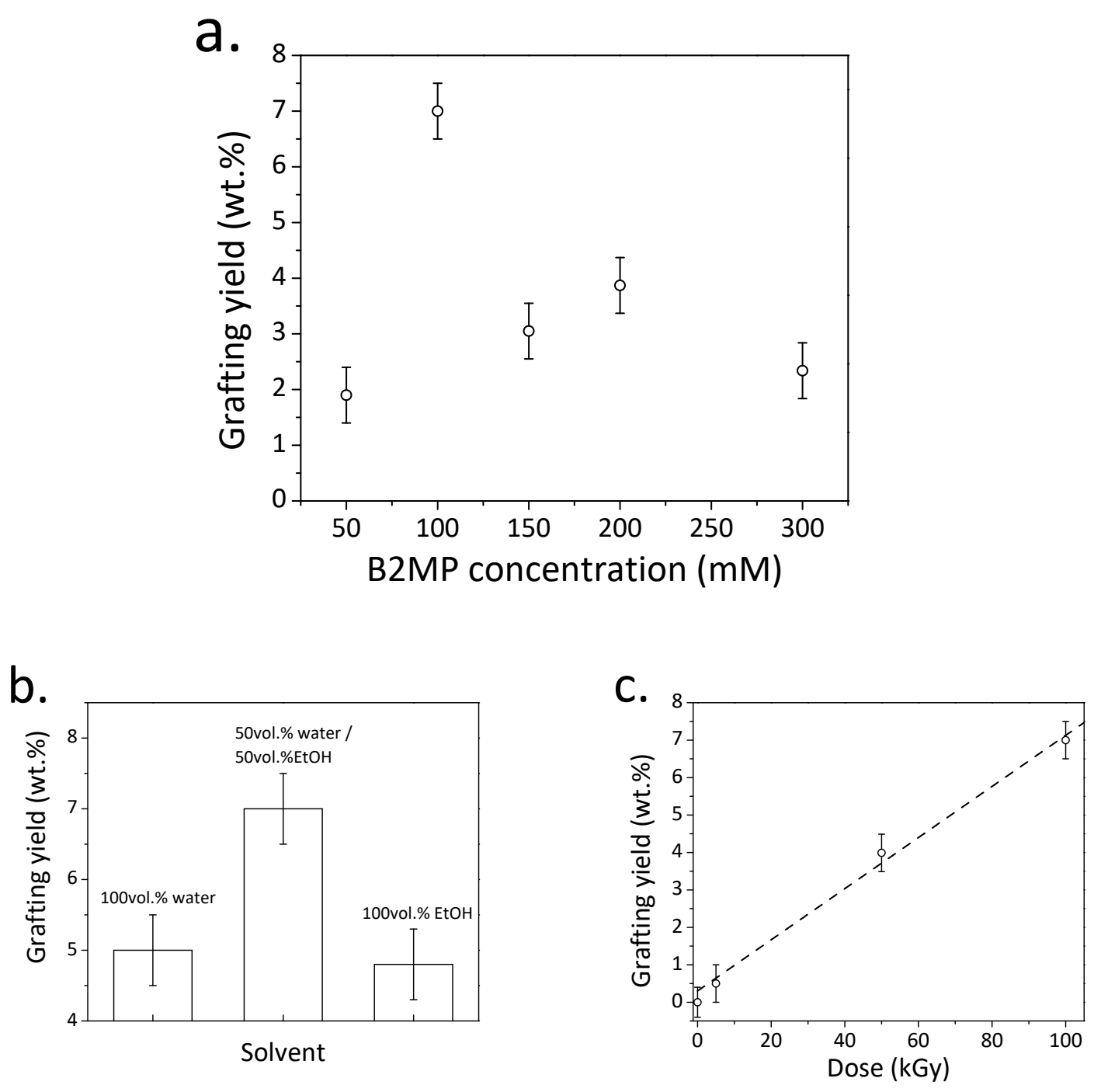

Figure 3. GY of electron-beam irradiated PVDF films depending on the (a) B2MP concentration at 100 kGy dose, 50 vol.\% water and 50 vol.\% ethanol solvent, (b) solvent at $100 \mathrm{kGy}$ dose, $100 \mathrm{mM} \mathrm{B} 2 \mathrm{MP}$, and (c) GY versus dose, $100 \mathrm{mM}$ B2MP, 50 vol.\% water and 50 vol.\% ethanol solvent ; PVDF film thickness is $9 \mu \mathrm{m}$.

3.3. B2MP radiation grafting into track-etched PVDF membranes. The fabrication procedure is comprised of several steps. Firstly, PVDF films were bombarded by SHI of ${ }_{136} \mathrm{Xe}^{48+}$ under He atmosphere. The ions, passing through the solid polymer film, induce continuous trails of excitations and ionizations along their pathways leading to the formation of latent tracks. Contrary to electrons, the deposited energy is highly localized along the ion trails [28]. Secondly, latent tracks are revealed by selective ion track etching in a highly oxidizing solution of $\mathrm{KOH}$ and $\mathrm{KMnO}_{4}$ resulting in the formation of cylindrical nanopores. The etching process does not remove all the radicals. Despite the fact that the remaining radical amount is relatively low, a localized radiografting occurs from the nanopore walls $[32,33]$. Once the radiation grafting parameters have been established for electron-beam irradiated PVDF films which are rich of radicals, the same grafting protocol (i.e. 50 vol.\% water and 50 vol.\% ethanol as solvent, $100 \mathrm{mM}$ B2MP concentration, $65^{\circ} \mathrm{C}$ grafting temperature, $18 \mathrm{~h}$ grafting time) was directly applied to the 
fabrication of B2MP-g-PVDF nanoporous membranes.

Figure 4a shows the EPR spectra of the PVDF track-etched membranes exposed to a $10{ }^{10} \mathrm{mcm}^{-2}$ fluence before and after grafting with B2MP. Figure $4 \mathrm{~b}$ displays the radical decay due to the addition of the B2MP. Since the addition of PVDF radicals to the B2MP gives a rise to the formation of the growing free radicals, it is expected that there is no change in a total radical concentration. However, as shown in figure $4 \mathrm{~b}$, there is tremendous decrease of the free radical concentration after addition of the B2MP. This may be explained by the fact that the decay of the PVDF radicals undergoes through various competing reactions. Since the GY is only about $3.5 \mathrm{wt} \%$, it seems that the reaction of B2MP addition is not a predominant one. To explain a disappearance of the free radicals in the absence of $\mathrm{KMnO}_{4}$, one would expect the PVDF radicals undergo either crosslinking or disproportionating reactions favored by temperature of the reaction. Nevertheless, in the presence of $\mathrm{KMnO}_{4}$, the disappearance of the free radicals of PVDF may be additionally due to the oxidation reactions through an electron transfer to potassium permanganate.
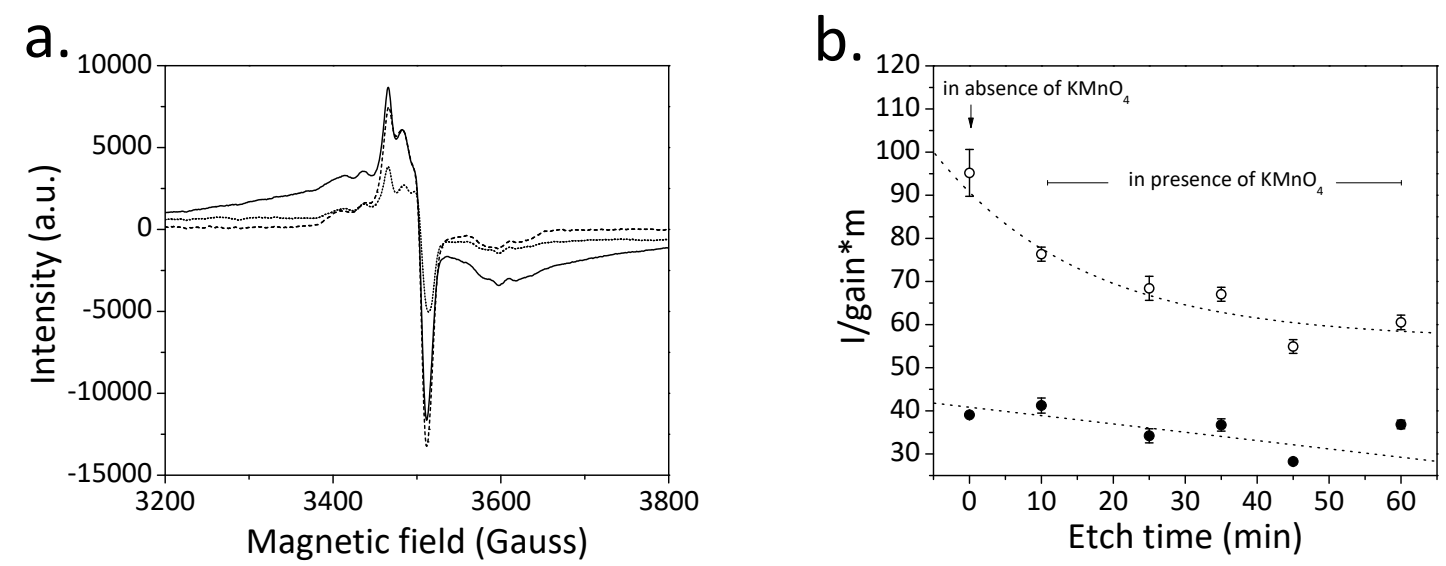

Figure 4. EPR spectra of track-etched PVDF membrane (a) before and after the radiation grafting, fluence $10{ }^{10} \mathrm{mcm}^{-2}$ : $25 \mathrm{~min}$ of etching (solid line), $25 \mathrm{~min}$ etching and $1 \mathrm{~h}$ grafting (dotted line), no etching (dashed line); (b) the radical consumption by grafting: (o) Etched during various times, $(\bullet)$ etched during various times and grafted within $1 \mathrm{~h}$.

Table 1 shows GYs under various irradiation conditions. As clearly demonstrated in the table, the optimal conditions were archived at $300 \mathrm{mM}$ B2MP concentration, 50 vol.\% water and 50 vol.\% ethanol as a solvent.

Figure 5 shows the chemical structure and of the B2MP and configuration of uranyl coordination by phosphate groups of B2MP [14].

FESEM was used to analyze the surface morphology of functionalized track-etched membranes. In microphotographs (figure 6) are shown a top view and cross section of B2MPg-PVDF membrane exposed to a $10{ }^{9} \mathrm{mcm}^{-2}$ fluence. Increasing the ion fluence from $10{ }^{9} \mathrm{mcm}^{-2}$ to $10^{10} \mathrm{mcm}^{-2}$ leads to the statistical overlapping of some pores. However, at higher pore density, more B2MP is exposed toward uranyl enabling the enhancement 
Table 1. GYs of track-etched PVDF under various grafting conditions.

\begin{tabular}{lcccr}
\hline $\begin{array}{l}\text { Fluence } \\
\mathrm{cm}^{-2}\end{array}$ & $\begin{array}{c}\text { Grafting time } \\
h\end{array}$ & $\begin{array}{c}\text { B2MP concentration } \\
m M\end{array}$ & Solvent mixture & GY \\
$w t . \%$
\end{tabular}<smiles>C=C(C)C(=O)OCCOP(=O)(O)OCCOC(=O)C(=C)C</smiles>

b.

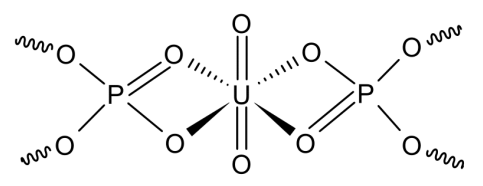

Figure 5. (a) Chemical structure of B2MP and (b) proposed configuration of uranyl coordination by phosphate groups of B2MP according to the ref. [14].

of loading capacity of the membranes. Therefore, the membranes exposed to a fluence of $10^{10} \mathrm{mcm}^{-2}$ had been used for sensor's fabrication in this work. Cryofracture was made in order to study the cross section of the membranes and to verify their openness after chemical etching. FESEM imaging of the cryofractured membrane showed that pores extended completely through the membrane and not blocked inside.
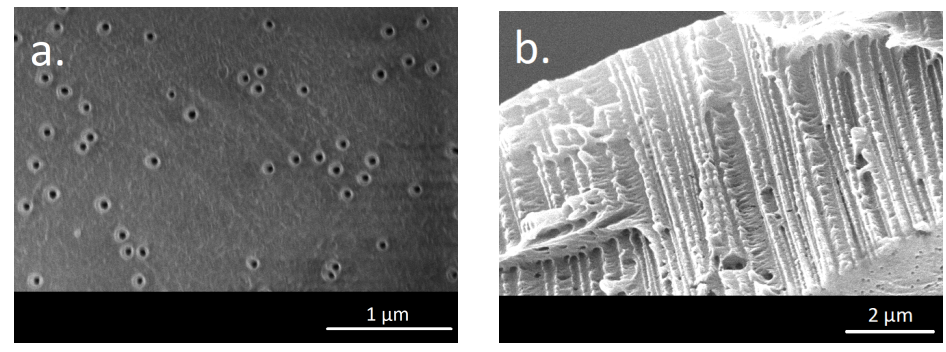

Figure 6. FESEM photo of (a) top view and (b) cross section of PVDF membrane after chemical etching, fluence $10{ }^{9} \mathrm{mcm}^{-2}$.

The presence of functional polymer inside cylindrical nanopores was verified by FTIR (figure 7a). The FTIR spectrum primarily demonstrates the characteristic absorption bands of PVDF [40] with a doublet corresponding to the $\mathrm{CH}_{2}$ vibrations at 2985 and 3025 $\mathrm{cm}^{-1}$, a multiplet with spectral absorption bands at 1453,1424, 1403 and $1385 \mathrm{~cm}^{-1}$ attributed to a mixture of $\mathrm{CH}_{2}$ and $\mathrm{C}-\mathrm{C}$ vibrations, two of the most intense absorption bands of $\mathrm{CF}_{2}$ at 1211 and $1183 \mathrm{~cm}^{-1}$ and PVDF skeleton vibration region between 900 and 400 $\mathrm{cm}^{-1}$. The latter region is attributed to the crystalline structure. The well-defined peak at $840 \mathrm{~cm}^{-1}$ represents $\beta$-phase of PVDF. Additional absorbance peaks were caused by 

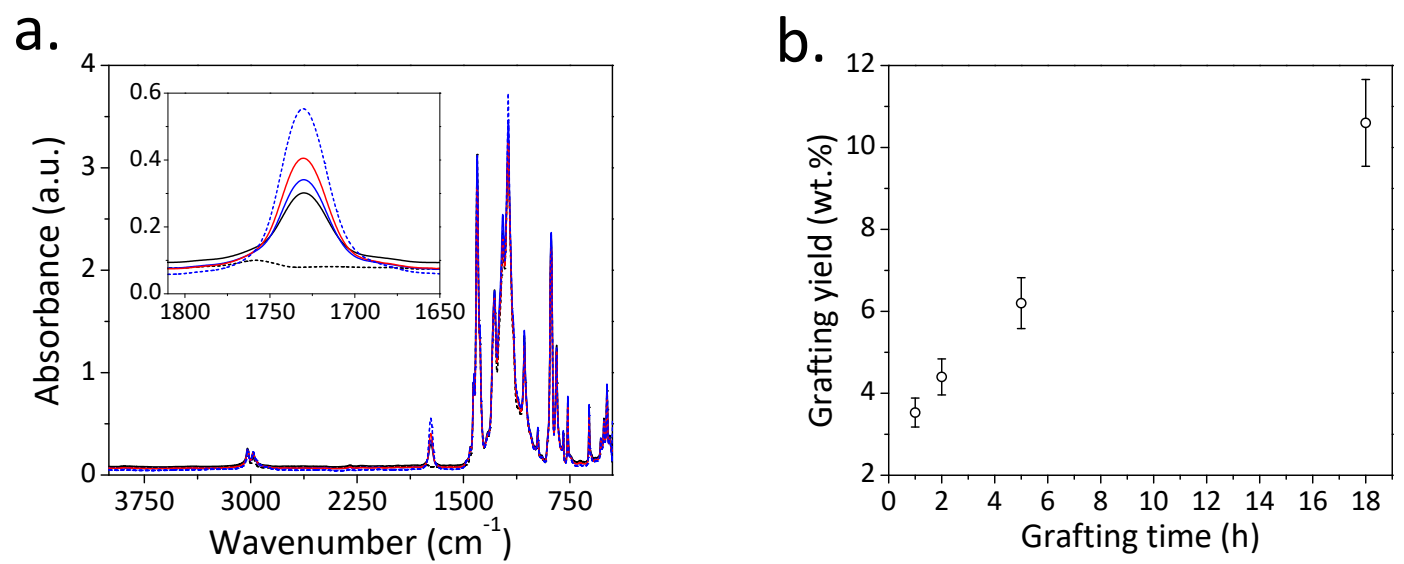

Figure 7. Functionalized B2MP-g-PVDF track-etched membranes analyses at various grafting times: (a) FTIR spectra of B2MP-g-PVDF : no grafting (dashed line), $1 \mathrm{~h}, 2 \mathrm{~h}, 5 \mathrm{~h}$ and $18 \mathrm{~h}$ of grafting (ascending in grafting time); (b) radiation grafting kinetics - grafting conditions : $300 \mathrm{mM} \mathrm{B} 2 \mathrm{MP}$ concentration in 50:50 vol\% ethanol/water solutions, fluence $10{ }^{10} \mathrm{~cm}^{-2}$ -

Notably, the absorbance peak at ca. $1725 \mathrm{~cm}^{-1}$ associated with the $-\mathrm{C}=\mathrm{O}$ vibration of the esters was clearly observed (inset in figure 7a). The absorption bands corresponding to the stretching vibrations of the $-\mathrm{P}=\mathrm{O}$, that typically appear at $1350-1250 \mathrm{~cm}^{-1}$ are not observable due to the overlap between these and PVDF absorption bands. The 1725 $\mathrm{cm}^{-1}$ peak increase with the grafting time is in coherence with quantitative GY results obtained by gravimetry (figure $7 \mathrm{~b}$ ). GYs rapidly increase within 4 hours and reach a plateau after 16-18 hours due to the diminution of monomer diffusion through the amorphous part of the PVDF.

XPS was used to confirm the presence of phosphate groups after radiation grafting of B2MP and its capability to trap uranyl ions. Figure 8 shows XPS spectra of the B2MP-g-PVDF membranes exposed to a fluence of $10{ }^{10} \mathrm{mcm}^{-2}$ before and after adsorption of uranyl. An intense peak in the survey spectrum of $F$ 1s arises from PVDF (figure 8a). The C 1s peak at ca. $285 \mathrm{eV}$ can be curved-fitted with six peaks (figure 9). Two main peaks with binding energies (BE) of $285.6 \mathrm{eV}$ and $290.1 \mathrm{eV}$ for $\mathrm{CH}_{2}$ and $\mathrm{CF}_{2}$ species, respectively, assigned to the PVDF main chains. Others, less intense, arise from $\mathrm{C}-\mathrm{C} / \mathrm{H},-\mathrm{C}=\mathrm{O},-\mathrm{C}-\mathrm{O}$ and $-\mathrm{O}-\mathrm{C}=\mathrm{O}$ groups of grafted $\mathrm{B} 2 \mathrm{MP}$. The revealed peak at $133 \mathrm{eV}$ (figure $8 \mathrm{~b}$ ) confirms the presence of the phosphate groups of B2MP whose position is in agreement with previous studies [34,35]. Evidently, no signal of uranyl was observed before uranyl adsorption (figure 8c). For the adsorption, the B2MP-g-PVDF membrane was immersed into a $2 \mathrm{mM}$ uranyl acetate solution for 18 hours. After the adsorption, oxygen atoms from the uranyl ion shield the phosphate group as they are more electronegative than phosphorus, causing a decrease of the $\mathrm{P}$ $2 \mathrm{p}$ peak intensity (figure $8 \mathrm{~d}$ ) and thus affirming $\mathrm{UO}_{2}^{2+}-\mathrm{B} 2 \mathrm{MP}$ complexation. Figure $8 \mathrm{e}$ shows the U 4f XPS spectrum of uranyl after the B2MP-g-PVDF membrane adsorbed uranyl ions. The two peaks of $\mathrm{U}$ assigned to the $\mathrm{U}_{7 / 2}$ and $\mathrm{U}_{5 / 2}$ possessing spin orbit splitting of $10.9 \mathrm{eV}$ were detected [36-38]. Deconvolution of $\mathrm{U} \mathrm{f}_{7 / 2}$ peak revealed 
two satellites at higher binding energies of $389.7 \mathrm{eV}$ and $386.1 \mathrm{eV}$. It agrees with previously published data and can be attributed to $\mathrm{U}^{5+}$ and $\mathrm{U}^{6+}$ in the uranyl cation [39,42-44].
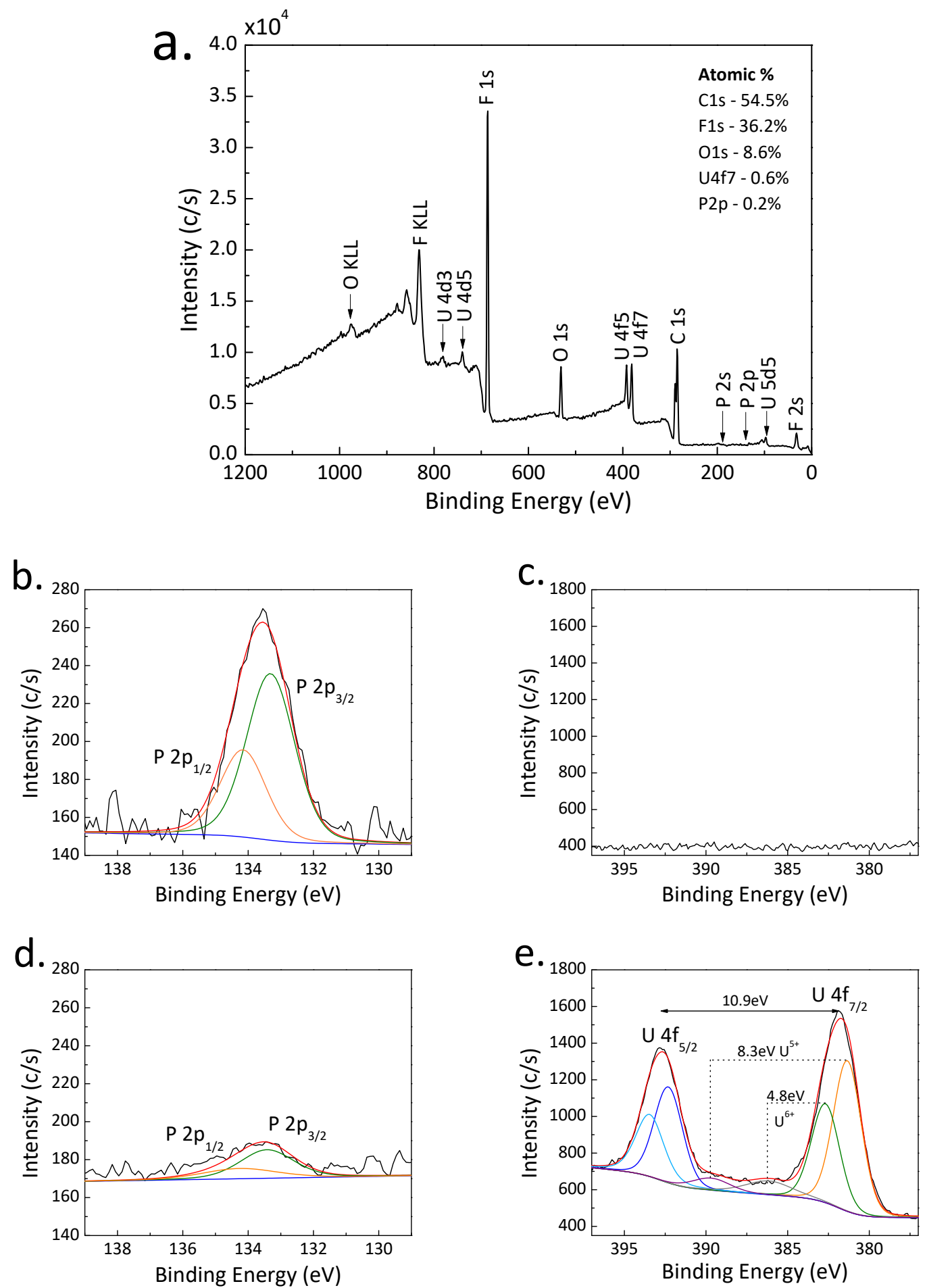

Figure 8. XPS spectra of B2MP-g-PVDF membrane of $10{ }^{10} \mathrm{mcm}{ }^{-2}$ fluence (GY of $3.5 \mathrm{wt} \%$ ) (a) Survey spectrum of B2MP-g-PVDF membrane after immersion into $2 \mathrm{mM}$ uranyl acetate solution for 18 hours. (b, d) P 2p peak of B2MP before and after uranyl adsorption respectively. (c, e) U 4f peak of uranyl before and after adsorption respectively. 


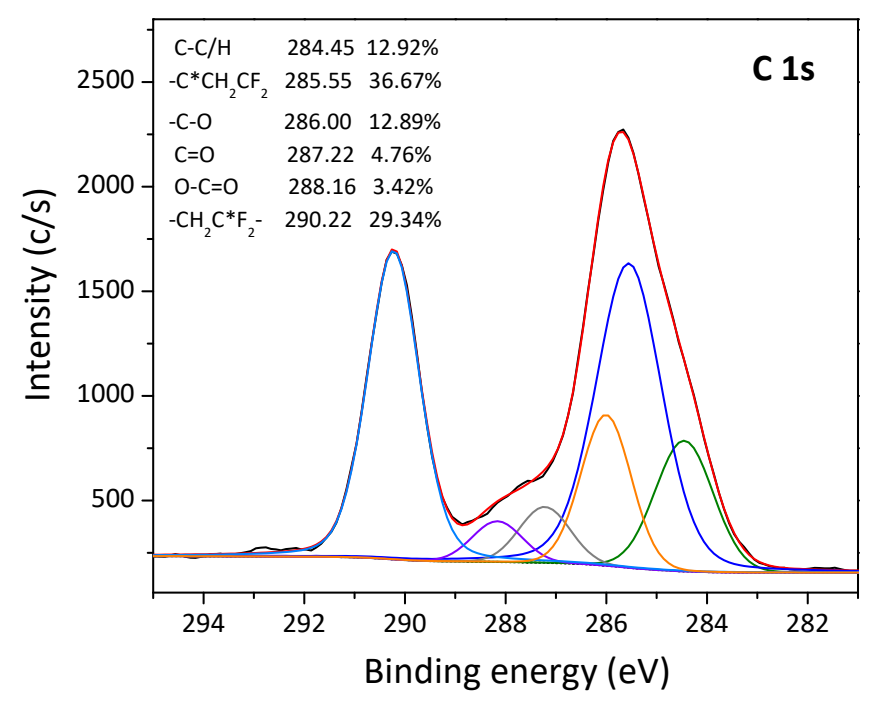

Figure 9. C1s peak deconvolution from XPS spectrum of B2MP-g-PVDF membrane of $10^{10} \mathrm{mcm}^{-2}$ fluence (GY of $3.5 \mathrm{wt} \%$ )

3.3. Electrochemical detection. The first step in developing an electroanalytical method was selecting the working electrode. In this work, a gold electrode was chosen as it is frequently used for low concentrations measurements of uranyl in aqueous solutions $[35,45,46]$. Another important choice was an electrolyte and $\mathrm{pH}$ as both parameters affect on redox mechanism of uranyl. Peled et al. report that $50 \mathrm{mM}$ acetate buffer $(\mathrm{pH} 3)$ with $100 \mathrm{mM} \mathrm{KNO}_{3}$ is the best medium for the detection of low concentration of uranyl in water [22].

To connect the membrane electrodes to a potentiostat, a home-made clip device was used for all voltammetric measurements (figure 10). The clip was made of Plexiglas (PMMA) with gold wires inserted in the clip to provide an electrical contact. A silver wire was used as a pseudo-reference electrode.
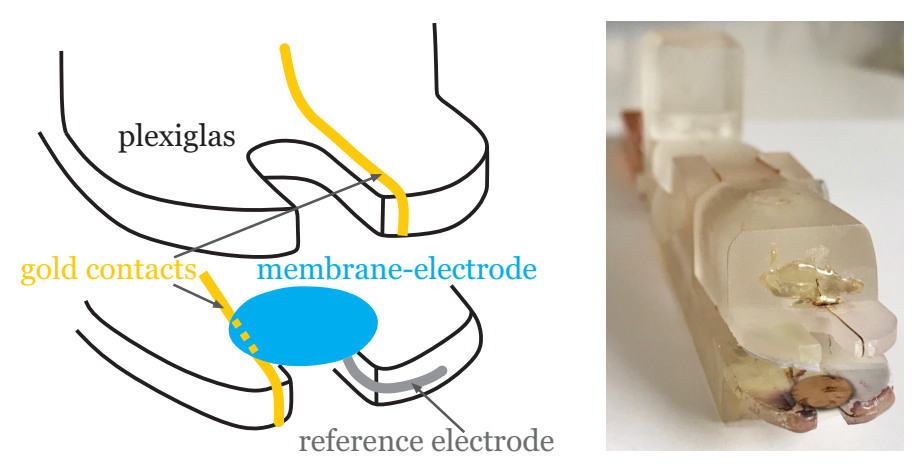

Figure 10. (a) Scheme of the clip set-up used for voltammetric measurements. (b) Photo of the clip with membrane electrode placed inside.

For the adsorption, membranes were placed in glass bottles containing polluted solutions 
and stirred using an orbital shaker for various times (from 30 min to 7 days). 2 hours of adsorption were found sufficient to get reproducible responses. During adsorption, uranyl, being a hard Lewis acid, tends to form a complex with phosphate ligands of B2MP. Proposed configuration of this $\mathrm{UO}_{2}^{2+}-\mathrm{B} 2 \mathrm{MP}$ complex according to the reference [14] is shown in figure 5b. Adsorbed uranyl ions were then analyzed by SW-CSV using acetate buffer $(50 \mathrm{mM})$ and $100 \mathrm{mM} \mathrm{KNO}_{3}(\mathrm{pH} 3)$ electrolyte. Cyclic voltammetry measurements were firstly performed in order to understand the reactions taking place in the system. Figure 11 shows B2MP-g-PVDF membrane-electrode CV curves in presence of electrolyte (black dotted) and electrolyte spiked with U(VI) at 3, 10 and 20 ppm. It can be seen that a reduction wave appears at $-0.003 \mathrm{~V}$ and an oxidation one at $0.54 \mathrm{~V}$ versus Ag wire pseudo-reference. These signals are associated with one-electron reduction and oxidation of uranyl (1. and 3. in figure 11) [47]. The second reduction wave, corresponding to the reduction of $\mathrm{UO}_{2}^{+}$to insoluble species $\mathrm{UO}_{2}$ (2. in figure 11), is observed at ca. $-0.5 \mathrm{~V}$. A second oxidation wave at ca. $0.6 \mathrm{~V}$ is related to the direct two-electron oxidation of $\mathrm{UO}_{2}$ to $\mathrm{UO}_{2}^{2+}$ species (4. in figure 11).

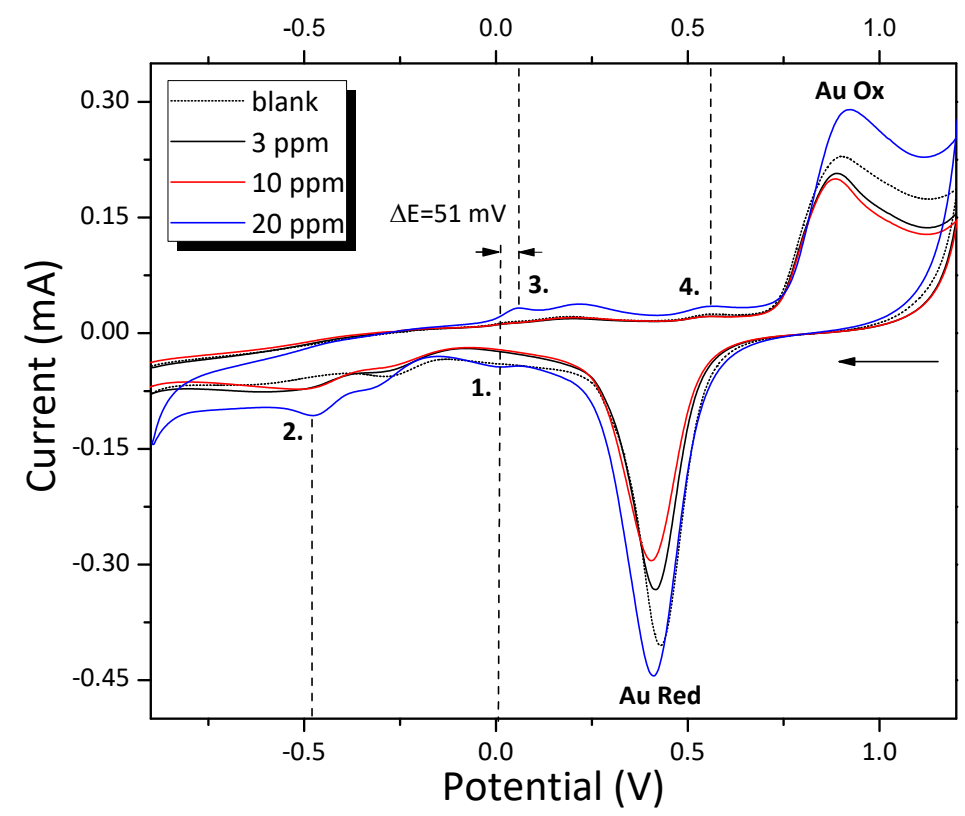

Figure 11. CV curves of B2MP-g-PVDF membrane-electrode in $50 \mathrm{mM}$ acetate buffer and $100 \mathrm{mM}$ $\mathrm{KNO}_{3}$ electrolyte spiked with U(VI) reaching 3, 10 and $20 \mathrm{ppm}$ (black, red, blue curves respectively). Reactions marked 1., 2., 3. and 4. are discussed in the text.

Several parameters such as deposition time, frequency, kinetic of adsorption were investigated. Registering the highest current of the reduction peak at $-0.5 \mathrm{~V}$ (reaction 2.) for a given $\mathrm{U}(\mathrm{IV})$-spiked electrolyte $(10 \mathrm{ppm})$ and a deposition potential of $+1.2 \mathrm{~V}$, the optimal deposition time on the cathode side of B2MP-g-PVDF membrane-electrode was found equal to $300 \mathrm{sec}$ and was further used for all the measurements. The chosen frequency was set at $20 \mathrm{~Hz}$ (figure 12 (left)) as it is a good compromise between current intensity optimization and reproducibility. Figure 12 (right) displays kinetics of adsorption registering the peak current intensity of $\mathrm{U}(\mathrm{VI})$ reduction peak. 

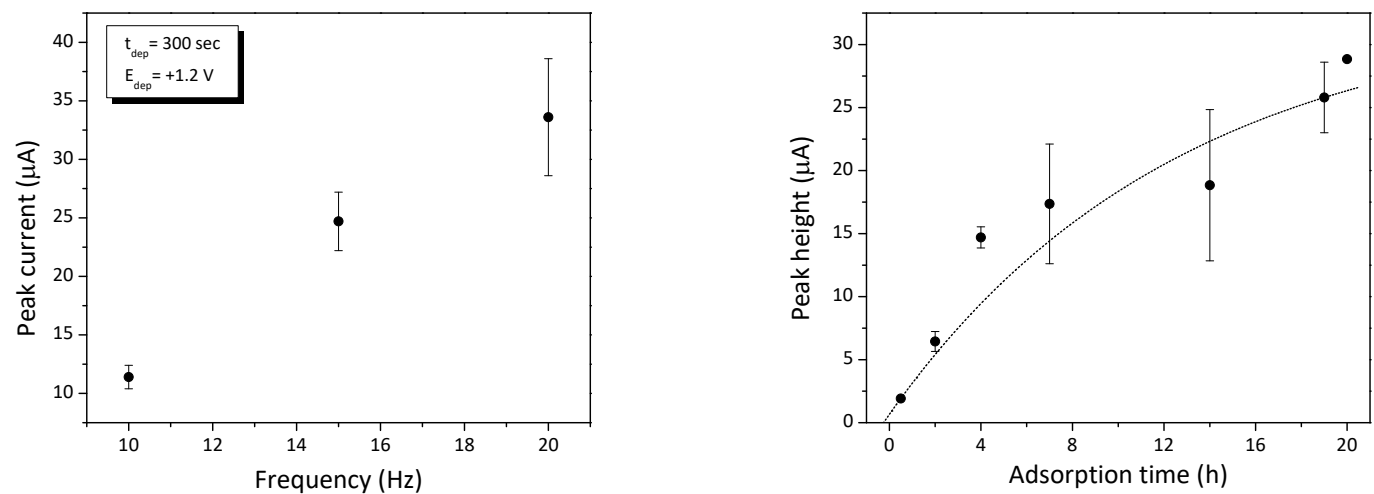

Figure 12. SW-CSV optimization of B2MP-g-PVDF membrane-electrodes doped with U(VI) ions : (left) frequency against current intensity of $\mathrm{U}(\mathrm{VI})$ reduction peak (500 ppb U(VI) concentration); (right) kinetics of adsorption as function of $\mathrm{U}(\mathrm{VI})$ reduction peak height (50 ppb U(VI) concentration). - deposition time : $300 \mathrm{sec}$; deposition potential : +1.2 V; GY of $3.5 \mathrm{wt} . \%$

As displays on figure 13a, the peak currents obtained from the first reduction peak at $-0.5 \mathrm{~V}$ were used to plot a calibration curve (figure $13 \mathrm{~b}$ ). The repeatability is $20 \%$ in average showing a good reproducibility between membrane-electrode batches. No problem of stability was observed after $2 \mathrm{~h}$ adsorption at neutral $\mathrm{pH}$.
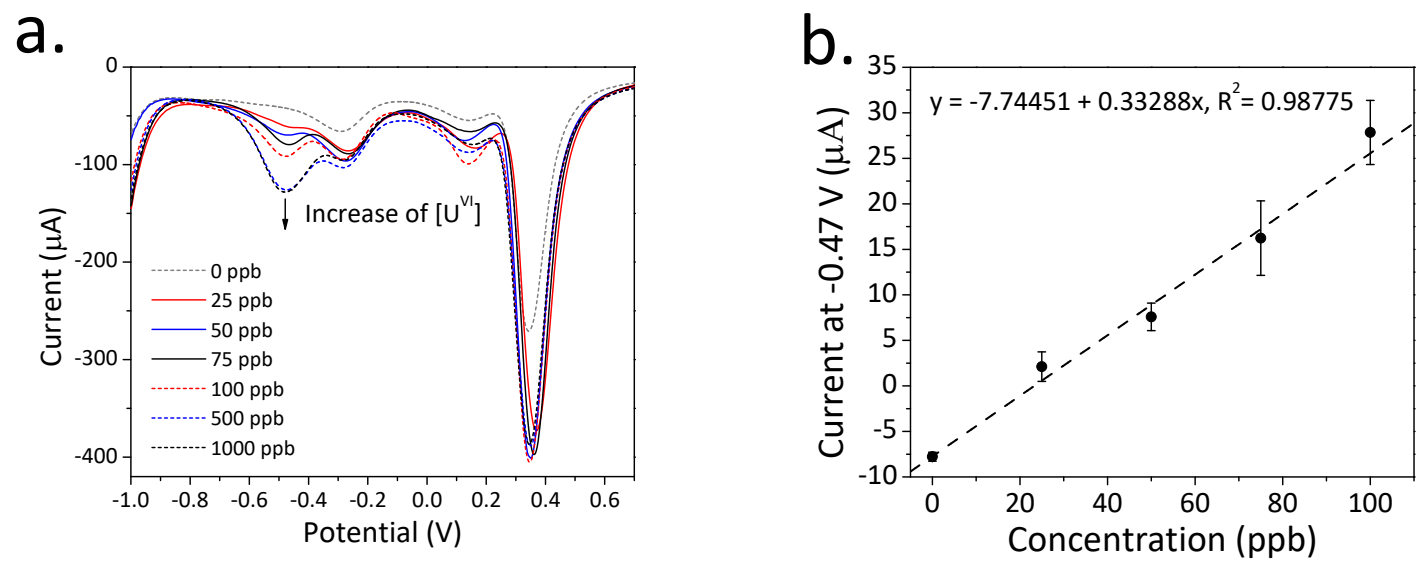

Figure 13. (a) SW-CSV curves recorded at various concentrations of uranyl: $0,25,50,75,100,500$, $1000 \mathrm{ppb}$ (uranyl reduction peak raises with concentration) in acetate buffer $(50 \mathrm{mM})$ and $100 \mathrm{mM} \mathrm{KNO}$ ( $\mathrm{pH} 3$ ) electrolyte at a deposition potential of $+1.2 \mathrm{~V}$ and deposition time of $300 \mathrm{sec}$, (b) calibration curve after 2 hours of adsorption at neutral $\mathrm{pH}$.

B2MP-g-PVDF nanoporous electrodes with a GY of 3.5 wt.\% were tested by SW-CSV for calibration curve establishment. It was shown that these functionalized membranes were sufficiently reactive toward U(VI) trapping and electrochemical detection (figure 13). Hence, it is recommended to limit the GY to facilitate ionic transport. The obtained calibration curve demonstrates sensitivity at the ppb-level. The limit of detection (3 $\sigma_{\bar{j}}$ slope) of the B2MP-g-PVDF membrane electrodes of $10^{10} \mathrm{mcm}^{-2}$ equals to $17 \mathrm{ppb}$, with a quantification limit (LOQ) of $51 \mathrm{ppb}$. 
The interferences of trapped U(VI) in B2MP-g-PVDF membrane-electrode with other metal ions during adsorption are shown in figure 14. The uranyl concentration equals to $100 \mathrm{ppb}$, while the concentrations of other metals is in 10-fold excess. Apart $\mathrm{Mg}(\mathrm{II})$, most of metal ions were found to interfere with $\mathrm{U}(\mathrm{VI})$. This result suggests a high instability of $\mathrm{UO}_{2}^{+}$ions, which can disproportionate to more stable species in presence of other salts leading to the $-0.5 \mathrm{~V}$ reduction peak suppression. More investigations are needed to pursue this study.

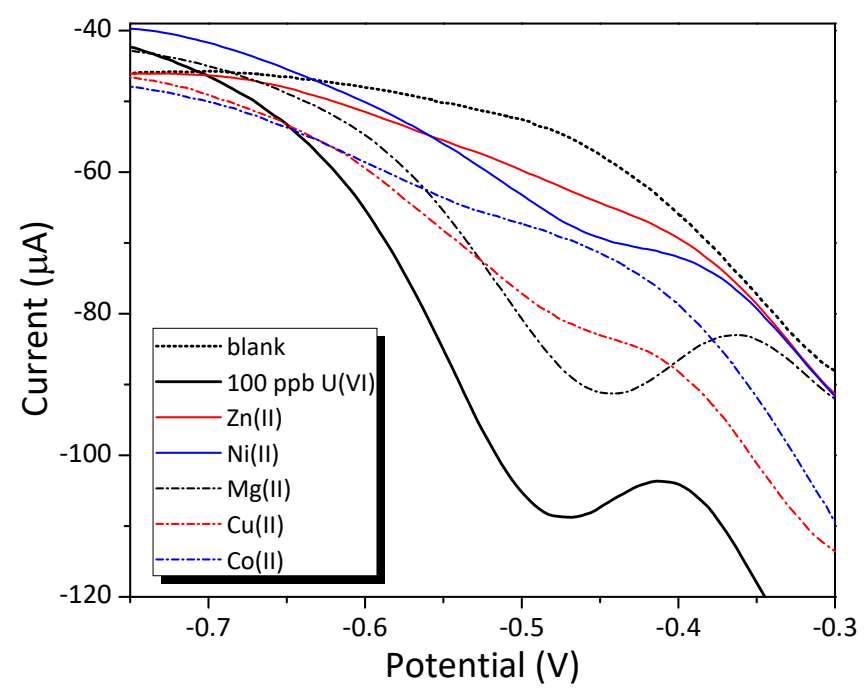

Figure 14. Interferences with some metal ions after $7 \mathrm{~h}$ of adsorption in 10 -fold excess ion concentration (100 ppb U(VI) concentration.

\section{CONCLUSIONS}

We have successfully developed a novel U(VI) electrochemical sensor based on radiation-induced grafting methodology of B2MP onto PVDF. The radiolytically produced C-centered free radicals of the PVDF initiate graft polymerization of the B2MP onto internal surface of cylindrical nanopores. Based on the relatively low grafting yield and the decay of C-centered free radicals of PVDF, our results suggest that there are different competitive reactions occurring during grafting. These competing reactions are radical-radical interactions, $\mathrm{PVDF}^{\cdot}+\mathrm{KMnO}_{4}$ electron transfer, and $\mathrm{PVDF}-\mathrm{B} 2 \mathrm{MP}{ }^{\bullet}$ chain growing reactions.

While the radical-radical interactions take place, crosslinking and disproportionation reactions occur, while at the same time the electron transfer from $\mathrm{PVDF}^{\cdot}$ to $\mathrm{KMnO}_{4}$ as a result of chemical etching cannot be underestimated. All these termination reactions explain a $60 \%$ radical decay observed by EPR after radiation grafting. Our results thus suggest that desired graft polymerization $\mathrm{PVDF}^{\circ}+\mathrm{B} 2 \mathrm{MP}$ may be not the predominant one. Despite these considerations, limiting the GY to low values (around $3.5 \mathrm{wt} . \%$ ) was found to produce advantageous membrane detection performance as this GY allowed the B2MP polymer to cover the inner surface of the cylindrical nanopores without blocking 
them.

The efficient uranyl uptake of B2MP-g-PVDF membranes points out that the geometry of the cylindrical nanopores provides a confinement that facilitates the coordination reaction between phosphate groups of the grafted B2MP and uranyl ions. In addition, the nanopores increase the surface area of the membrane which leads to higher loading capacities by increasing the amount of B2MP exposed to uranyl. The higher loading capacities validated the construction of a novel electrochemical sensor capable of monitoring uranyl in water through the conversion of the membrane into an electrode.

To validate the proof of concept for U(VI) sensoring, a calibration plot obtained by means of SW-CSV demonstrates a ppb-level sensitivity of the sensors toward dissolved uranyl ions (LOD is $17 \mathrm{ppb}$ ). The LOD might be lowered using more efficient agitation during adsorption.

As a prospective goal, the B2MP-g-PVDF membranes might also be used in nanofiltration for uranium removal. However, our results have demonstrated that the presence of high salt concentration in water strongly affects the U(VI) electrochemical response. Deeper electrochemical studies on U(VI) speciation in real waters are needed.

\section{Acknowledgements}

Authors acknowledge the IDI Ph.D. funding of the Université Paris Saclay for financial support of this work. The authors are grateful to the EMIR committee, SIRIUS team of LSI and CIMAP team at GANIL for their strong implication in irradiation experiments. The authors would also thank Bruno Boizot for his encouraging assistance in EPR measurements and Marco Sangermano for XPS consultancy.

\section{References}

[1] F. Edition, "Guidelines for drinking-water quality," WHO chronicle, vol. 38, no. 4, pp. 104-8, 2011.

[2] P. Kurttio, A. Auvinen, L. Salonen, H. Saha, J. Pekkanen, I. Mäkeläinen, S. B. Väisänen, I. M. Penttilä, and H. Komulainen, "Renal effects of uranium in drinking water." Environmental health perspectives, vol. 110, no. 4, p. 337, 2002.

[3] S. H. Frisbie, E. J. Mitchell, and B. Sarkar, "World health organization increases its drinking-water guideline for uranium," Environmental Science: Processes \& Impacts, vol. 15, no. 10, pp. 1817-1823, 2013.

[4] J. H. Aldstadt, J. M. Kuo, L. L. Smith, and M. D. Erickson, "Determination of uranium by flow injection inductively coupled plasma mass spectrometry," Analytica chimica acta, vol. 319, no. 1-2, pp. 135-143, 1996.

[5] D. Solatie, P. Carbol, P. Peerani, and M. Betti, "Investigation of separation/purification methodologies for the determination of $232 \mathrm{u}$ and 236pu in solution of spent nuclear fuels by $\alpha$-spectrometry," Radiochimica Acta, vol. 89, no. 9, pp. 551-556, 2001. 
[6] J. M. Boncella, "Inorganic chemistry: Uranium gets a reaction," Nature, vol. 451, no. 7176, p. 250, 2008.

[7] E. Billo, "Modern inorganic chemistry (jolly, william 1.)," 1985.

[8] R. Davies, J. Kennedy, R. McIlroy, R. Spence, and K. Hill, "Extraction of uranium from sea water," Nature, vol. 203, no. 4950, pp. 1110-1115, 1964.

[9] H. Egawa and H. Harada, "Recovery of uranium from sea water by using chelating resins containing amidoxime groups," Nippon Kagaku Kaishi, vol. 1979, no. 7, pp. 958959, 1979.

[10] A. Mellah, S. Chegrouche, and M. Barkat, "The removal of uranium (vi) from aqueous solutions onto activated carbon: kinetic and thermodynamic investigations," Journal of colloid and interface science, vol. 296, no. 2, pp. 434-441, 2006.

[11] M. Tsezos, "Recovery of uranium from biological adsorbents-desorption equilibrium," Biotechnology and bioengineering, vol. 26, no. 8, pp. 973-981, 1984.

[12] M. Tamada, "Current status of technology for collection of uranium from seawater," in International Seminar On Nuclear War And Planetary Emergencies-42nd Session. World Scientific, 2010, pp. 243-252.

[13] N. Seko, A. Katakai, S. Hasegawa, M. Tamada, N. Kasai, H. Takeda, T. Sugo, and K. Saito, "Aquaculture of uranium in seawater by a fabric-adsorbent submerged system," Nuclear Technology, vol. 144, no. 2, pp. 274-278, 2003.

[14] S. Das, A. Pandey, A. Athawale, V. Kumar, Y. Bhardwaj, S. Sabharwal, and V. Manchanda, "Chemical aspects of uranium recovery from seawater by amidoximated electron-beam-grafted polypropylene membranes," Desalination, vol. 232, no. 1-3, pp. 243-253, 2008.

[15] T. C. Dietz, C. E. Tomaszewski, Z. Tsinas, D. Poster, A. Barkatt, M. Adel-Hadadi, F. B. Bateman, L. T. Cumberland, E. Schneider, K. Gaskell et al., "Uranium removal from seawater by means of polyamide 6 fibers directly grafted with diallyl oxalate through a single-step, solvent-free irradiation process," Industrial \& engineering chemistry research, vol. 55, no. 15, pp. 4179-4186, 2015.

[16] P. Ilaiyaraja, A. K. S. Deb, K. Sivasubramanian, D. Ponraju, and B. Venkatraman, "Adsorption of uranium from aqueous solution by pamam dendron functionalized styrene divinylbenzene," Journal of hazardous materials, vol. 250, pp. 155-166, 2013.

[17] Q. Cao, Y. Liu, C. Wang, and J. Cheng, "Phosphorus-modified poly (styrene-codivinylbenzene)-pamam chelating resin for the adsorption of uranium (vi) in aqueous," Journal of hazardous materials, vol. 263, pp. 311-321, 2013.

[18] S. Das, A. K. Pandey, A. A. Athawale, V. Natarajan, and V. K. Manchanda, "Uranium preconcentration from seawater using phosphate functionalized poly (propylene) fibrous membrane," Desalination and Water Treatment, vol. 38, no. 1-3, pp. 114-120, 2012.

[19] D. Beltrami, G. Cote, H. Mokhtari, B. Courtaud, B. A. Moyer, and A. Chagnes, "Recovery of uranium from wet phosphoric acid by solvent extraction processes," Chemical reviews, vol. 114, no. 24, pp. 12 002-12 023, 2014. 
[20] M. Al-Sheikhly, T. Dietz, Z. Tsinas, C. Tomaszewski, I. M. Pazos, O. Nigliazzo, W. Li, M. Adel-Hadadi, and A. Barkatt, "Enhancement of extraction of uranium from seawater," Univ. of Maryland, Tech. Rep., 2016.

[21] S. Girgin, N. Acarkan, and A. A. Sirkeci, "The uranium (vi) extraction mechanism of d2ehpa-topo from a wet process phosphoric acid," Journal of radioanalytical and nuclear chemistry, vol. 251, no. 2, pp. 263-271, 2002.

[22] Y. Peled, E. Krent, N. Tal, H. Tobias, and D. Mandler, "Electrochemical determination of low levels of uranyl by a vibrating gold microelectrode," Analytical chemistry, vol. 87, no. 1, pp. 768-776, 2014.

[23] A. Becker, H. Tobias, and D. Mandler, "Electrochemical determination of uranyl ions using a self-assembled monolayer," Analytical chemistry, vol. 81, no. 20, pp. 86278631, 2009.

[24] H. Bessbousse, I. Nandhakumar, M. Decker, M. Barsbay, O. Cuscito, D. Lairez, M.-C. Clochard, and T. L. Wade, "Functionalized nanoporous track-etched $\beta$-pvdf membrane electrodes for lead (ii) determination by square wave anodic stripping voltammetry," Analytical Methods, vol. 3, no. 6, pp. 1351-1359, 2011.

[25] H. Bessbousse, N. Zran, J. Fauléau, B. Godin, V. Lemée, T. Wade, and M.-C. Clochard, "Poly (4-vinyl pyridine) radiografted pvdf track etched membranes as sensors for monitoring trace mercury in water," Radiation Physics and Chemistry, vol. 118, pp. 48-54, 2016.

[26] J.C. Hoogvliet, M. Dijksma, B. Kamp, W.P. van Bennekom, “Electrochemical pretreatment of polycrystalline gold electrodes to produce a reproducible surface roughness for self assembly : A study in phosphate buffer $\mathrm{pH}$ 7.4" anal. chem., vol. 72, no. 9, pp. 2016-2021, 2000.

[27] A. Fina, A. Lemoel, J.P. Duraud, M.T. Valin, C. Legressus, E. Balanzat, J.M. Ramillon, C. Darnez, "Surface processes occurring on PVDF under energetic ion irradiation" Nucl. Inst. and Meth. in Physics Research, B vol. 42, no. 1, pp. 69-75, 1989.

[28] E. Balanzat, S. Bouffard, A. Lemoel, N. Betz,"Physico-chemical modifications induced in polymers by swift heavy ions" Nucl. Inst. and Meth. in Physics Research, B vol. 91, no. 1-4, pp. 140-145, 1994.

[29] E. Adem, G. Burillo, E. Munoz, J. Richards, L. Cota, M. Avalos-Borja, "Electron and proton irradiation of poly(vinylidene fluoride): characterization by electron paramagnetic resonance" Polymer Degradation adn Stability, B vol. 81, no. 1, pp. 75-79, 2003.

[30] JS. Forsythe, DJT. Hill, "The radiation chemistry of fluoropolymers" Progress in Polymer Science, vol. 25.1, pp. 101-136, 2000.

[31] C. Aymes-Chodur, S. Esnouf, A. Lemoel, "ESR studies in $\gamma$-irradiated and PS-radiation grafted poly(vinylidene fluoride) " Journal of Polymer Science Part B: Polymer Physics, vol. 39.13, pp. 1437-1448, 2001.

[32] M. Barsbay, O. Güven, H. Bessbousse, T. L. Wade, F. Beuneu, and M.-C. Clochard, "Nanopore size tuning of polymeric membranes using the raft-mediated radical polymerization," Journal of membrane science, vol. 445, pp. 135-145, 2013. 
[33] O. Cuscito, M.-C. Clochard, S. Esnouf, N. Betz, and D. Lairez, "Nanoporous $\beta$-pvdf membranes with selectively functionalized pores," Nuclear Instruments and Methods in Physics Research Section B: Beam Interactions with Materials and Atoms, vol. 265, no. 1, pp. 309-313, 2007.

[34] D. M. Spori, N. V. Venkataraman, S. G. Tosatti, F. Durmaz, N. D. Spencer, and S. Zürcher, "Influence of alkyl chain length on phosphate self-assembled monolayers," Langmuir, vol. 23, no. 15, pp. 8053-8060, 2007.

[35] A. Becker, H. Tobias, Z. Porat, and D. Mandler, "Detection of uranium (vi) in aqueous solution by a calix [6] arene modified electrode," Journal of Electroanalytical Chemistry, vol. 621, no. 2, pp. 214-221, 2008.

[36] G. C. Allen, J. A. Crofts, M. T. Curtis, P. M. Tucker, D. Chadwick, and P. J. Hampson, "X-ray photoelectron spectroscopy of some uranium oxide phases," Journal of the Chemical Society, Dalton Transactions, no. 12, pp. 1296-1301, 1974.

[37] E. Ordonez-Regil, R. Drot, E. Simoni, and J. Ehrhardt, "Sorption of uranium (vi) onto lanthanum phosphate surfaces," Langmuir, vol. 18, no. 21, pp. 7977-7984, 2002.

[38] Y. Al-Salik, I. Al-Shankiti, and H. Idriss, "Core level spectroscopy of oxidized and reduced cexu1- xo2 materials," Journal of Electron Spectroscopy and Related Phenomena, vol. 194, pp. 66-73, 2014.

[39] T. Filippov, D. Svintsitskiy, I. Chetyrin, I. Prosvirin, D. Selishchev, and D. Kozlov, "Photocatalytic and photochemical processes on the surface of uranyl-modified oxides: An in situ xps study," Applied Catalysis A: General, vol. 558, pp. 81-90, 2018.

[40] N. Betz, A. Le Moel, E. Balanzat, J.M. Ramillon, J. Lamotte, J.P. Gallas, G. Jaskierowicz "A FTIR study of PVDF irradiated by means of Swift Heavy Ions" Journal of Polymer Science: Part B: Polymer Physics, vol. 32, pp. 1493-1502, 1994.

[41] A.A.L. Goncalves, A.C. Fonseca, I.G.P. Fabela, J.F.J. Coelho, A.C. Serra "Synthesis and characterization of high performance superabsorbent hydrogels using bis (2(methacryloyloxy) ethyl) phosphate as crosslinker" Express Polymer Letters, vol. 10, no. 3, pp. 248-258, 2016.

[42] E. S. Ilton and P. S. Bagus, "Xps determination of uranium oxidation states," Surface and Interface Analysis, vol. 43, no. 13, pp. 1549-1560, 2011.

[43] M. Schindler, F. Hawthorne, M. Freund, and P. Burns, "Xps spectra of uranyl minerals and synthetic uranyl compounds. i: The u $4 \mathrm{f}$ spectrum," Geochimica et Cosmochimica Acta, vol. 73, no. 9, pp. 2471-2487, 2009.

[44] S. A. McMaster, R. Ram, F. Charalambous, M. I. Pownceby, J. Tardio, and S. K. Bhargava, "Synthesis and characterisation of the uranium pyrochlore betafite [(ca, u) 2 (ti, nb, ta) 2o7]," Journal of hazardous materials, vol. 280, pp. 478-486, 2014.

[45] G. Billon and C. M. van den Berg, "Gold and silver micro-wire electrodes for trace analysis of metals," Electroanalysis: An International Journal Devoted to Fundamental and Practical Aspects of Electroanalysis, vol. 16, no. 19, pp. 1583-1591, 2004.

[46] R. K. Shervedani and S. A. Mozaffari, "Preparation and electrochemical characterization of a new nanosensor based on self-assembled monolayer of cysteamine functional- 
ized with phosphate groups," Surface and Coatings Technology, vol. 198, no. 1-3, pp. 123-128, 2005.

[47] H.G. Heal, "Electrochemistry of uranium” Nature, vol. 157, no. 3982, pp. 225-225, 1946. 